\title{
A case of anti-neutrophil cytoplasmic antibody-associated vasculitis with anti-glomerular basement membrane antibodies that was successfully treated with mizoribine as a safe and effective remission maintenance therapy with prednisolone and plasma exchange
}

\author{
Yuki lkeda $^{1}$ - Kenichi Fukunari ${ }^{1}$. Saori Uchiumi ${ }^{1}$ - Yuki Awanami ${ }^{1}$. Akiko Kanaya ${ }^{1} \cdot$ Keiichiro Matsumoto $^{2}$. \\ Makoto Fukuda $^{2} \cdot$ Tsuyoshi Takashima $^{2} \cdot$ Motoaki Miyazono $^{2} \cdot$ Yuji Ikeda $^{2}$
}

Received: 12 August 2018 / Accepted: 29 September 2019 / Published online: 14 October 2019

(c) The Author(s) 2019

\begin{abstract}
We herein report the case of myeloperoxidase (MPO) anti-neutrophil cytoplasmic antibody (ANCA)-associated vasculitis with anti-glomerular basement membrane (anti-GBM) antibody positivity that successfully treated with mizoribine (MZR) as an immunosuppressive drug for remission maintenance therapy after the initiation of dialysis in addition to plasma exchange (PE) and glucocorticoid treatment to control the disease condition. A 79-year-old woman developed serious renal dysfunction and pulmonary alveolar hemorrhaging due to MPO-ANCA and anti-GBM antibody double-positive vasculitis. She was started on hemodialysis and was treated with methylprednisolone (m-PSL) pulse therapy with PE, followed by oral prednisolone (PSL). The pulmonary alveolar hemorrhaging disappeared, and both antibody titers immediately decreased but then rose again. Thus, m-PSL pulse therapy performed again in combination with combined with MZR treatment. Her poor renal function was irreversible; however, this therapy decreased both antibody titers, and they did not increase again. The patient developed pancytopenia and hyperuricemia. It was considered likely that these conditions developed in association with MZR treatment. We, therefore, measured the patient's blood concentration of MZR, and the maintenance dose was finally set at $50 \mathrm{mg}$ after each dialysis session. The patient's pancytopenia and hyperuricemia improved and PSL could be smoothly tapered. This is the first case report of the use of MZR for remission maintenance therapy in a patient on hemodialysis who was positive for both ANCA and anti-GBM antibodies. The findings suggest that MZR can be used safely and effectively in such cases.
\end{abstract}

Keywords Anti-glomerular basement membrane (anti-GBM) antibody · Anti-neutrophil cytoplasmic antibody (ANCA) . Mizoribine $\cdot$ Hemodialysis

\section{Introduction}

As the initial treatment of anti-neutrophil cytoplasmic antibody (ANCA)-associated vasculitis (AAV) with antiglomerular basement membrane (anti-GBM) antibody

Yuki Ikeda

ikechine.4@gmail.com

1 Department of Nephrology, Sasebo Kyosai Medical Center, 10-17 Shimanjityo, Sasebo, Nagasaki 857-8575, Japan

2 Department of Internal Medicine, Faculty of Medicine, Saga University, Saga, Japan positivity, many patients receive plasma exchange (PE) with glucocorticoid (GC) and cyclophosphamide (CYA) combination therapy in the acute phase of the disease to treat antiGBM antibody-type rapidly progressive glomerulonephritis. For subsequent maintenance therapy, immunosuppressive drugs, such as azathioprine (AZA), mycophenolate mofetil (MMF), and methotrexate (MTX), are administered [1]. However, immunosuppressive drugs are associated with a high risk of serious adverse events, such as pancytopenia or infection, in patients with renal failure and elderly patients.

We herein report a case of myeloperoxidase (MPO)-ANCA-associated vasculitis with anti-GBM antibody positivity that was successfully treated with mizoribine 
(MZR) as an immunosuppressive drug for remission maintenance therapy after the initiation of dialysis in addition to $\mathrm{PE}$ and GC treatment to control the disease condition. The patient did not experience any serious adverse events, and the patient's blood levels of MZR were monitored throughout the clinical course.

\section{Case report}

The patient was a 79-year-old Japanese woman who had received medical treatment from her local doctor for hyperlipidemia and hypertension. Her renal function had been normal until 1 year previously. Gross hematuria appeared 4 days before her presentation to a local clinician, and general fatigue appeared 2 days before her presentation. She was found to have anemia and severe renal dysfunction (serum creatinine: $10.78 \mathrm{mg} / \mathrm{dL}$ ) and was transferred to our hospital in December 2016. She was treated for asthma using Breo Ellipta as an inhalant and had suffered from interstitial pneumonia for several years, but showed no tendency toward exacerbation. Her family history, life history, and allergy history were unremarkable.

On admission, her height was $142.1 \mathrm{~cm}$, and her body weight was $51.2 \mathrm{~kg}$. Her vital signs were as follows: body temperature, $36.7{ }^{\circ} \mathrm{C}$; blood pressure, 209/104 $\mathrm{mmHg}$; pulse rate, 102 beats/min and regular; respiratory rate, 20 breaths/ min; and $\mathrm{SpO}_{2}, 97 \%$ (on room air). The palpebral conjunctiva showed slight pallor. Fine crackles were heard in both lower lung fields, and pitting edema was observed in both legs.

The laboratory data showed inflammation (CRP, $6.69 \mathrm{mg}$ / dL) without leukocytosis (white blood cell count, $8910 / \mu \mathrm{L}$ ), normocytic anemia (serum hemoglobin, $7.6 \mathrm{~g} / \mathrm{dL}$ ), serious renal dysfunction (serum blood urea nitrogen, $82.1 \mathrm{mg} / \mathrm{dL}$; creatinine, $11.27 \mathrm{mg} / \mathrm{dL}$ ), and massive urinary protein (UP/ $\mathrm{UC}, 13.71 \mathrm{~g} / \mathrm{gCr}$ ) with a large number of poikilocytes. The serum MPO-ANCA and anti-GBM antibody levels were both elevated to $609 \mathrm{EU} / \mathrm{mL}$ and 19.6 EU/mL, respectively. In addition, her serum was positive for antinuclear antibodies (640 times), especially anti-centromere antibodies (elevated to $10.7 \mathrm{U} / \mathrm{mL}$ ), but she showed no symptoms such as Raynaud's phenomenon or calloused skin to suggest scleroderma. In addition, her serum KL-6 and SP-D levels were elevated to $1069 \mathrm{U} / \mathrm{mL}$ and $175.4 \mathrm{ng} / \mathrm{mL}$, respectively, suggesting interstitial pneumonia. The detailed laboratory data on admission are shown in Table 1.

Plain chest computed tomography (CT) showed a honeycomb pattern and slight linear reticulation at the base of both lungs. It was a usual interstitial pneumonia pattern. CT

Table 1 Laboratory findings on admission

\begin{tabular}{|c|c|c|c|c|c|}
\hline \multicolumn{2}{|l|}{ Peripheral blood } & \multicolumn{2}{|c|}{ Blood chemistry } & \multicolumn{2}{|l|}{ Serology } \\
\hline WBC & $8910 / \mu \mathrm{L}$ & $\mathrm{TP}$ & $6.9 \mathrm{~g} / \mathrm{dL}$ & CRP & $6.69 \mathrm{mg} / \mathrm{dL}$ \\
\hline $\mathrm{Neu}$ & $84.1 \%$ & Alb & $3.2 \mathrm{~g} / \mathrm{dL}$ & $\mathrm{IgG}$ & $1480 \mathrm{mg} / \mathrm{dL}$ \\
\hline Lympho & $12.0 \%$ & T-Bil & $0.22 \mathrm{mg} / \mathrm{dL}$ & $\operatorname{Ig} \mathrm{A}$ & $354 \mathrm{mg} / \mathrm{dL}$ \\
\hline Mono & $1.9 \%$ & AST & $11 \mathrm{U} / \mathrm{L}$ & $\operatorname{IgM}$ & $134 \mathrm{mg} / \mathrm{dL}$ \\
\hline Eosino & $0.1 \%$ & ALT & $5 \mathrm{U} / \mathrm{L}$ & MPO-ANCA & $609 \mathrm{EU}$ \\
\hline $\mathrm{RBC}$ & $259 \times 10^{4} / \mu \mathrm{L}$ & $\mathrm{LDH}$ & 267 1U/L & Anti-GBM antibody & 19.6 EU \\
\hline $\mathrm{Hb}$ & $7.6 \mathrm{~g} / \mathrm{dL}$ & CPK & $71 \mathrm{U} / \mathrm{L}$ & ANA & 640 times \\
\hline $\mathrm{Ht}$ & $22.8 \%$ & Uric acid & $8.00 \mathrm{mg} / \mathrm{dL}$ & Anti-centromere antibody & $10.7 \mathrm{U} / \mathrm{mL}$ \\
\hline \multirow[t]{5}{*}{ PIT } & $18.0 \times 10^{4} / \mu \mathrm{L}$ & BUN & $82.1 \mathrm{mg} / \mathrm{dL}$ & KL-6 & $1069 \mathrm{U} / \mathrm{mL}$ \\
\hline & & $\mathrm{Cr}$ & $11.27 \mathrm{mg} / \mathrm{dL}$ & SP-D & $175.4 \mathrm{ng} / \mathrm{mL}$ \\
\hline & & $\mathrm{Na}$ & $139 \mathrm{mEq} / \mathrm{L}$ & & \\
\hline & & $\mathrm{K}$ & $4.99 \mathrm{mEq} / \mathrm{L}$ & & \\
\hline & & $\mathrm{Cl}$ & $111.1 \mathrm{mEq} / \mathrm{L}$ & & \\
\hline Urinalysis & & $\mathrm{Ca}$ & $8.3 \mathrm{mg} / \mathrm{dL}$ & Blood gas analysis & \\
\hline Protein & $3+$ & IP & $8.9 \mathrm{mg} / \mathrm{dL}$ & PH & 7.206 \\
\hline Occult blood & $3+$ & Blood sugar & $130 \mathrm{mg} / \mathrm{dL}$ & $\mathrm{pCO}_{2}$ & $32.2 \mathrm{mmHg}$ \\
\hline Sugar sediment & $2+$ & HbAlc & $4.8 \%$ & $\mathrm{HCO}_{3}^{-}$ & $12.3 \mathrm{mmol} / \mathrm{L}$ \\
\hline $\mathrm{RBC}$ & $>100$ HPF dysmorphic & & & B.E & -14.6 \\
\hline WBC & 10-19 HPF & & & Anion gap & $16.2 \mathrm{mEq} / \mathrm{L}$ \\
\hline \multicolumn{6}{|l|}{ Urine chemistry } \\
\hline NAG & $22.5 \mathrm{U} / \mathrm{L}$ & & & & \\
\hline $\mathrm{P} / \mathrm{C}$ ratio & $13.71 \mathrm{~g} / \mathrm{gCr}$ & & & & \\
\hline $\mathrm{p} 2 \mathrm{MG}$ & $102,860 \mathrm{ng} / \mathrm{mL}$ & & & & \\
\hline
\end{tabular}


also showed infiltrative shadow and a frosted glass shadow that spread diffusely throughout the whole lung field, which was not a typical finding of interstitial pneumonia (Fig. 1). Although we could not deny that these shadows indicated pneumonia, we considered them to reflect pulmonary alveolar hemorrhage due to the presence of blood in the sputum.

Based on these findings, we diagnosed the patient with AAV with anti-GBM antibody. There were no signs or symptoms of vasculitis except in the kidneys and lungs. Her Birmingham Vasculitis Activity Score was 18 points.

The patient was dialyzed from day 2 and was treated methylprednisolone (m-PSL) pulse therapy at dose of $1 \mathrm{~g} /$ day with PE (FFP $40 \mathrm{U}$ ) for 3 days starting the same day, followed by oral prednisolone (PSL) at a dose of $40 \mathrm{mg} /$ day. With regard to the PE content, we used OP-02 W (Asahi KASEI) as a dialysis membrane, and used nafamostat mesylate to prevent the coagulation of the perfusion blood (initial dose, $0 \mathrm{mg}$; sustained dose, $25 \mathrm{mg} / \mathrm{h}$ ). We performed daily plasma exchange for 3 days using FFP (40 Units/time as a substitute liquid), blood flow, $150 \mathrm{cc} / \mathrm{min}$; separated plasma flow, $50 \mathrm{cc} / \mathrm{min}$.

Both antibody titers decreased immediately but rose again from day 12 . Thus, the patient received m-PSL pulse therapy at a dose of $0.5 \mathrm{~g} /$ day for 3 days again from day 20, with MZR (50 mg/day) added from day 23. In previous reports, MZR was only administered for patients who continued hemodialysis for several years with repeated recurrence of ANCA-related vasculitis [2, 3]. However, in the present case, it was administered at the induction of hemodialysis, and her daily urine flow was still $300-500 \mathrm{cc}$. We, therefore, set the dose to $50 \mathrm{mg}$ per day. These therapies reduced the levels of both antibodies, and they did not increase again (Fig. 2).

The patient developed pancytopenia and hyperuricemia, likely as adverse events of MZR, from day 28. We, therefore, measured the patient's blood concentration of MZR at 3,4 , and $5 \mathrm{~h}$ after administration $(\mathrm{C} 3, \mathrm{C} 4$, and $\mathrm{C} 5)$ during hemodialysis (HD) (Fig. 3). When MZR was administered daily, the blood concentration increased over time and over the weekend. The maximum blood concentration ( $\mathrm{Cmax}$ ) was $3.51 \mu \mathrm{g} / \mathrm{mL}$ before dialysis at the beginning of the week. Because the concentration was not so high, we suspected sulfamethoxazole trimethoprim (used to prevent pneumocystis) to be the most likely source of the adverse event and stopped its administration. However, the pancytopenia and hyperuricemia did not improve after the cessation of this drug; thus, we considered MZR to be the cause of these adverse events and reduced the dosage. The maintenance dose of MZR was ultimately set at $50 \mathrm{mg}$ after each dialysis session. Thereafter, the pancytopenia and hyperuricemia improved.

The maximum blood concentration when MZR was administered at a dose of $50 \mathrm{mg}$ per dialysis session was $1.49 \mu \mathrm{g} / \mathrm{mL}$ (Fig. 3). Despite reducing the dosage of MZR, both antibody titers continued to decrease, and PSL could be smoothly tapered. Although pancytopenia and hyperuricemia developed as side effects, the severity was mild. The minimum of WBC count, $\mathrm{Hb}$ level, and Plt count were as follows: $3250 / \mu \mathrm{L}$ (no grade), $8.9 \mathrm{~g} / \mathrm{dl}$ (Grade 1), and 57,000/ $\mu \mathrm{L}$ (Grade 2), and there was no signs of gouty attack or other physiological abnormalities, although the maximum UA level was $>10 \mathrm{mg} / \mathrm{dl}$ (Grade 1; National Cancer Institute Common Terminology Criteria for Adverse Events v3.0) [4]. We did not perform a renal biopsy, because the patient presented with dyspnea in the acute phase. She already had severe renal dysfunction and her kidneys seemed to be atrophic on ultrasonography and computed tomography. She also suffered from heparin-induced thrombocytopenia from day 19. We were unable to confirm the linear deposition of $\mathrm{IgG}$ to the glomerular basement membrane by a renal biopsy in this case, so we did not prove directly that the elevated titer of anti-GBM antibody in her blood test was associated with a disease condition. There is also a possibility

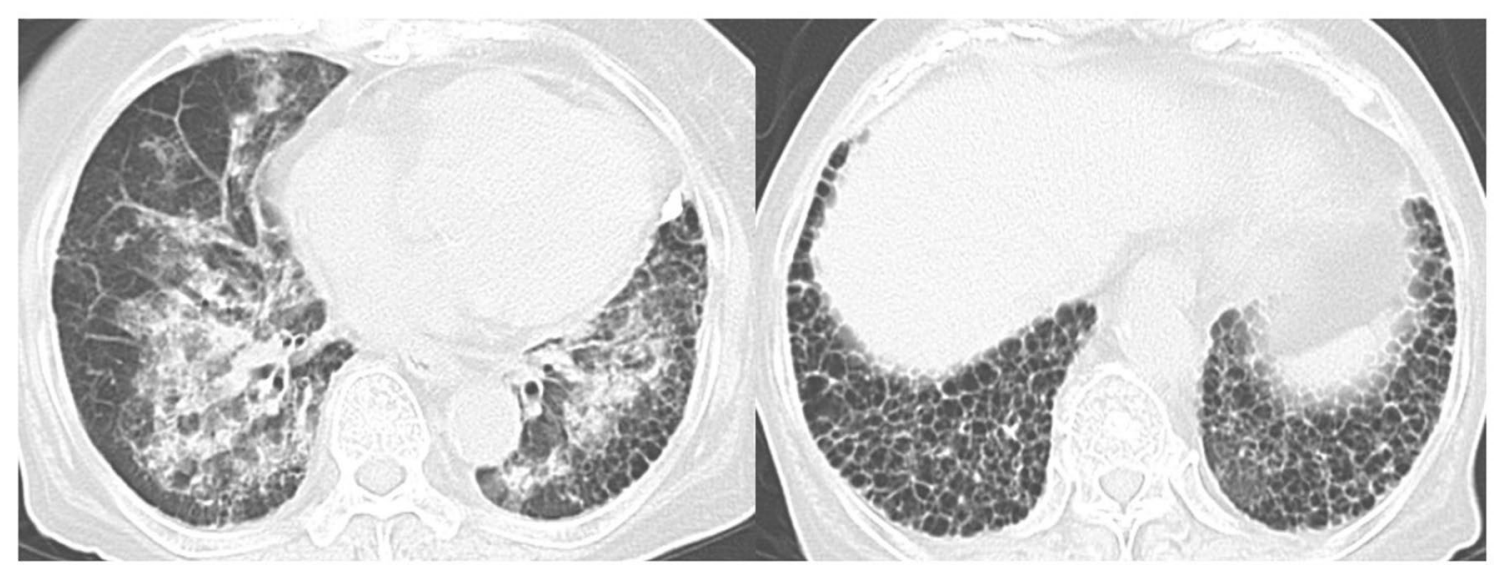

Fig. 1 Computed tomography images of the lungs 


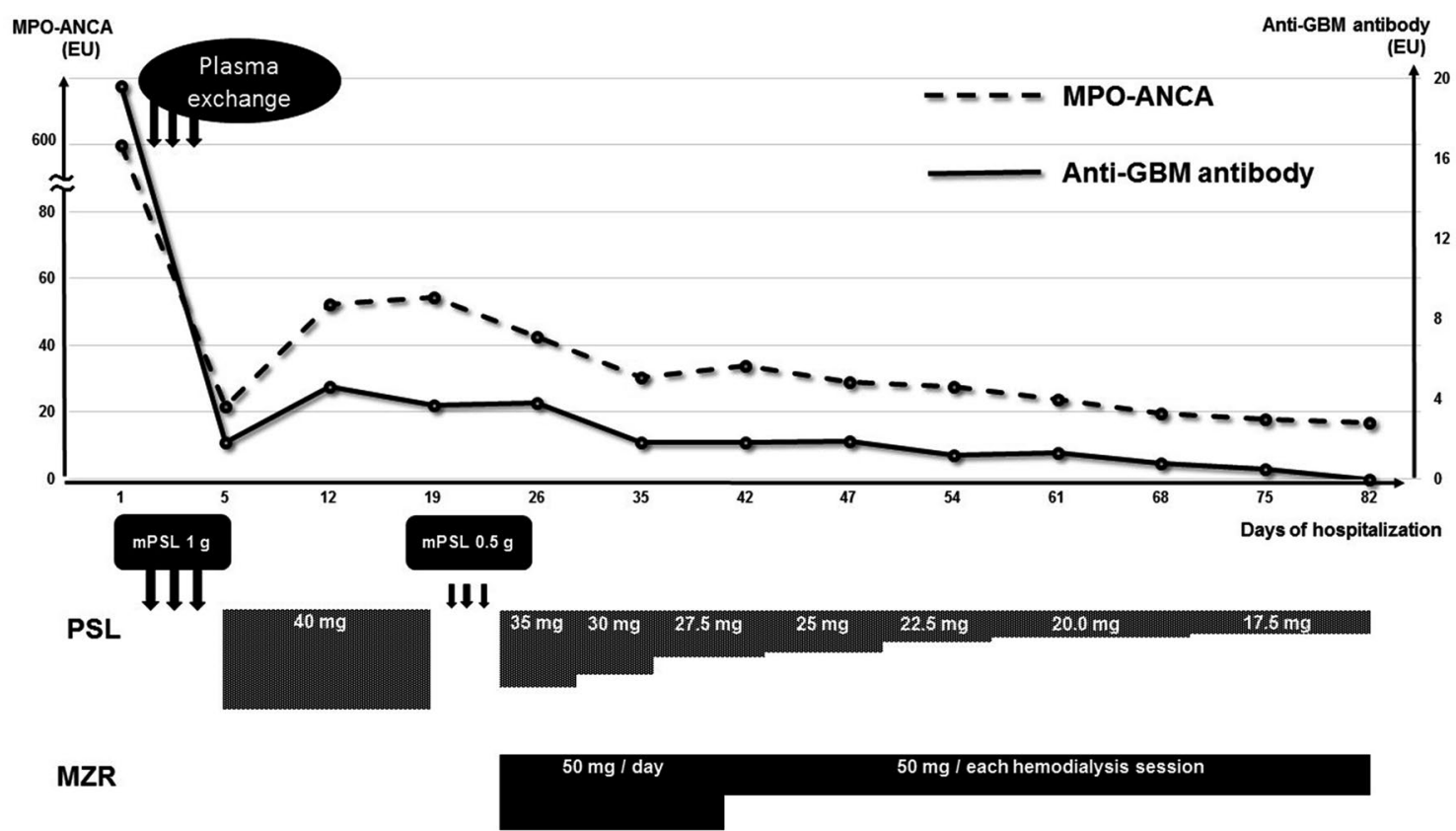

Fig. 2 Clinical course
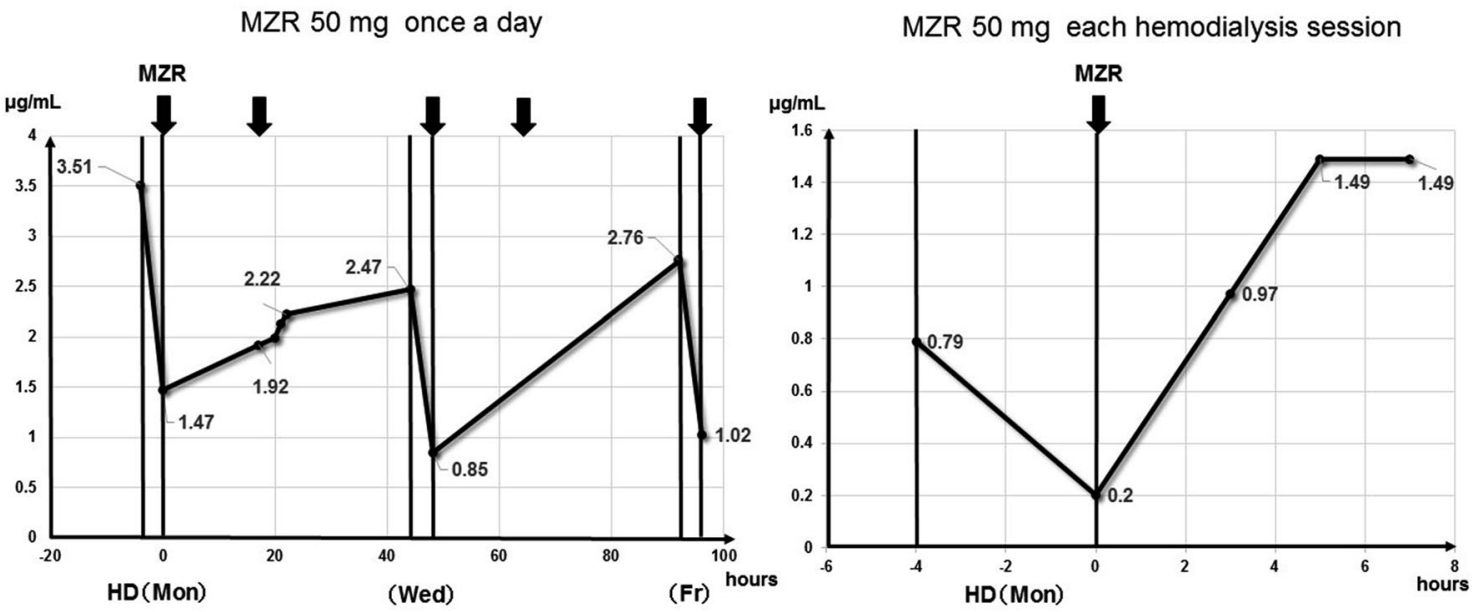

Fig. 3 Blood concentration of mizoribine

that elevated level of anti-GBM antibody was associated with hypergammopathy. However, we cannot exclude the possibility that the elevated titer of the anti-GBM antibody was not related to the pathogenicity of the disease, as the titer was low.

\section{Discussion}

Cases involving patients who are positive for both ANCA and anti-GBM antibody (double-positive) are believed to be relatively rare. However, double-positive cases have been reported to account for $9.36 \%$ of patients with AAV [5]. The prognosis of double-positive cases is debatable $[1,6$, 7]. McAdoo et al. retrospectively analyzed the clinical features and long-term outcomes of a large cohort of $568 \mathrm{AAV}$ patients from 4 European centers, including 41 patients with anti-GBM antibody disease and 37 double-positive patients, and reported that among the double-positive patients, older patients and patients with a longer duration of symptoms before the diagnosis were likely to have AAV (age distribution showed one peak [60-75 years], and symptom duration was longer than 10-12 weeks). However, in the acute phase, the clinical course of the double-positive group closely 
resembles that of anti-GBM antibody disease, which is associated with serious renal failure and pulmonary alveolar hemorrhaging in approximately one-third of patients. The present case shared some similarities with respect to advanced age and complication with pulmonary alveolar hemorrhage in the acute phase.

It has also been reported that the anti-GBM antibody titers of double-positive patients tend to be lower in comparison with patients who are positive for anti-GBM antibody alone, and the renal survival of the double-positive group was shown to be better than that of patients positive for anti-GBM antibody alone and not better than in the AAV group; however, there were no marked differences in the overall survival of the groups. With respect to the treatment of the double-positive group, as mentioned above, many cases in the acute phase received PE followed by combination therapy with GC and CYA, and immunosuppressive drugs (e.g., AZA, MMF, and MTX) were often administered as maintenance therapy ( $74 \%$ of double-positive patients were reportedly receiving immunosuppressive drugs at 6 months). However, approximately half of double-positive patients relapsed within the 4.8-year follow-up period, and the majority of patients were not receiving maintenance treatment with immunosuppressive drugs [1].

The prolonged use of immunosuppressive drugs such as CYA or AZA is associated with a high risk of pancytopenia and severe infection; thus, physicians hesitate to prescribe these drugs, especially to elderly patients. All immunosuppressive drugs, including MZR, are associated with a risk of infection due to the side effect of myelosuppression. Furthermore, their dosage must be reduced in patients with CKD [8]. To administer these drugs safely, it is important to-when possible - measure their blood levels, and to cease their administration if the blood level becomes high. The blood level of MZR can be measured and the drug is eliminated by dialysis; thus, it is relatively easy to control the blood level. For this reason, MZR we be used more safely in comparison with other immunosuppressive drugs (e.g., CYA or AZA).

In the present case, although the patient had received $\mathrm{PE}$ in addition to GC therapy in the early phase, which controlled the pulmonary alveolar hemorrhaging, both the ANCA and anti-GBM antibody titers rose again. However, we were able to decrease both antibody titers again by adding MZR as an immunosuppressive drug without severe adverse events by monitoring the blood concentration of MZR.

MZR is an inhibitor of nucleic acid synthesis and has effects similar to AZA and MMF [9]. Dialysis is the only metabolic pathway for this drug in anuric patients on hemodialysis, because MZR is mainly eliminated via urine [10]. A mean of $43 \%$ of the drug was reported to be removed by 4-h dialysis [11]. While the concentration at $3 \mathrm{~h}$ after the administration of MZR is generally equivalent to the Cmax in patients with a normal kidney function and $\mathrm{C} 3$ monitoring is recommended to adjust the dosage of MZR [12], the Cmax is known to be delayed in patients on dialysis, and the concentration has been shown to be maintained until the next dialysis session $[2,3]$. When the serum concentration of MZR is $1.0 \mu \mathrm{g} / \mathrm{mL}$, activation of lymphocytes is suppressed by approximately $50 \%$, and when the concentration is $0.8-3.0 \mu \mathrm{g} / \mathrm{mL}$, MZR binds to $14-3-3$ protein and activates a steroid receptor [7, 13]. Adverse events, such as liver dysfunction or pancytopenia, increase when blood levels exceed $5 \mu \mathrm{g} / \mathrm{mL}[8,13]$.

There have been a few reports in which MZR was administered to AAV patients on hemodialysis, and we found two relevant reports. One case was received MZR $(75 \mathrm{mg})$ after each dialysis session as remission maintenance therapy for $\mathrm{AAV}$; the other received MZR $(50 \mathrm{mg})$ after each dialysis session at the time of a relapse of AAV. In those cases, the Cmax of MZR was $0.53-1.84 \mu \mathrm{g} / \mathrm{mL}[2,3]$. In the present case, the administration of MZR $(50 \mathrm{mg})$ after each dialysis session with the Cmax of MZR controlled at $1.49 \mu \mathrm{g} /$ $\mathrm{mL}$ was effective for AAV with ANCA and anti-GBM antibody double positivity and no severe adverse events were observed.

Acknowledgements The authors thank Asahi-Kasei Pharm, Nagasaki, Japan, for performing the measurements and analysis of the blood levels of MZR.

\section{Compliance with ethical standards}

Conflict of interest The authors declare that they have no conflict of interest.

Human and animal rights This article does not report any studies with human participants or animals performed by the authors.

Open Access This article is distributed under the terms of the Creative Commons Attribution 4.0 International License (http://creativeco mmons.org/licenses/by/4.0/), which permits unrestricted use, distribution, and reproduction in any medium, provided you give appropriate credit to the original author(s) and the source, provide a link to the Creative Commons license, and indicate if changes were made.

\section{References}

1. McAdoo SP, Tanna A, Hrušková Z, et al. Patient double-seropositive for ANCA and anti-GBM antibodies have varied renal survival, frequency of relapse, and outcomes compared to singleseropositive patients. Kidney Int. 2017;92:693-702.

2. Tokunaga M, Tamura M, Kabashima N, et al. A case report of steroid-resistant antineutrophil cytoplasmic antibody-related vasculitis successfully treated by mizoribine in a hemodialysis patient. Ther Apher Dial. 2009;13:77-9.

3. Nakamura G, Homma N, Sakamaki Y, et al. Mizoribine as a safe and effective combined maintenance therapy with prednisolone 
for anti-neutrophil cytoplasmic antibody-associated vasculitis in a hemodialysis patient. CEN Case Rep. 2013;2:139-43.

4. Trotti A, Colevas AD, Setser A, et al. CTCAE v3.0: development of a comprehensive grading system for the adverse effects of cancer treatment. Semin Radiat Oncol. 2003;13(3):176-81.

5. Zhao J, Yang R, Cui Z, et al. Characteristics and outcome of Chinese patients with both antineutrophil cytoplasmic antibody and antiglomerular basement membrane antibodies. Nephron Clin Pract. 2007;107:56-62.

6. Rutgers A, Slot M, van Paassen P, et al. Coexistence of antiglomerular basement membrane antibodies myeloperoxidaseANCAs in crescentic glomerulonephritis. Am J Kidney Dis. 2005;46:253-62.

7. Takahashi S, Wakui H, Gustafsson JA, et al. Functional interaction of the immunosuppressant mizoribine with the 14-3-3 protein. Biochem Biophys Res Commun. 2000;21:87-92.

8. Nishioka Y, Horita Y, Tadokoro M, et al. Mizoribine induces remission of relapsed ANCA-associated renal vasculitis. Nephrol Dial Transpl. 2006;21:1087-8.

9. Hirayama K, Kobayashi M, Hashimoto Y, et al. Treatment With the purine synthesis inhibitor mizoribine for ANCA-associated renal vasculitis. Am J Kidney Dis. 2004;44:57-63.
10. Kawasaki Y. Mizoribine: a new approach in the treatment of renal disease. Clin Dev Immunol. 2009;2009:681482.

11. Takada K, Yoshikawa H, Muranishi S, et al. Elimination characteristics of bredinin from patients serum in hemodialysis. Int $\mathrm{J}$ Clin Pharmacol Ther Toxicol. 1985;23:197-9.

12. Fuke T, Abe Y, Hibino S, et al. Mizoribine requires individual dosing due to variation of bioavailability. Pediatr Int. 2012;54:885-91.

13. Sonda K, Takahashi K, Tanabe K, et al. Clinical pharmacokinetic study of mizoribine in renal transplantation patients. Transpl Proc. 1996;28:3643-8.

Publisher's Note Springer Nature remains neutral with regard to jurisdictional claims in published maps and institutional affiliations. 